Check for updates

Cite this: RSC Adv., 2017, 7, 25867

Received 8th February 2017

Accepted 9th May 2017

DOI: $10.1039 / \mathrm{c} 7 \mathrm{ra0} 01605 \mathrm{k}$

rsc.li/rsc-advances

\title{
A facile one-step fabrication of a novel Cu/MoS 2 nano-assembled structure for enhanced hydrogen evolution reaction performance $\uparrow$
}

\begin{abstract}
Jiamu Cao, (D) a Jing Zhou, ${ }^{a}$ Yufeng Zhang ${ }^{\star a b}$ and Xiaowei Liu ${ }^{\text {ab }}$
The design and synthesis of non-precious-metal catalysts for the efficient electrochemical transformation of water into molecular hydrogen in acid environments are of paramount importance in reducing energy losses during the water splitting process. Here, unique hybrid nanostructures of $\mathrm{Cu} / \mathrm{MoS}_{2}$ have been prepared by a one-pot microwave-assisted synthesis. The resultant nano-assembled catalyst has excellent hydrogen evolution reaction (HER) electrocatalytic properties, including an overpotential of as low as $120 \mathrm{mV}$, a Tafel slope of $55 \mathrm{mV} \mathrm{dec}{ }^{-1}$, and a remarkable cycling stability. The observed outstanding catalytic performance can be attributed to $\mathrm{Cu}$ nanoparticles (NPs) that improved not only the electrical conductivity of the catalyst but also the catalytic activity by a synergistic effect with the edge exposed, nano-sized $\mathrm{MoS}_{2}$. These findings confirmed that this earth-abundant material was a useful catalyst for water splitting.
\end{abstract}

\section{Introduction}

Hydrogen is a scalable and renewable energy that, once produced, is environmentally and climatically clean over the entire length of its conversion chains, from production to utilization. ${ }^{1}$ These advantages are enough to make it a promising alternative energy source to address the existing environmental emission issues from fossil energy. ${ }^{2}$ Due to its sustainability, water splitting has become one of the most promising approaches for hydrogen production. ${ }^{3}$ During the HER, the advanced electrocatalyst is a key component that reduces the overpotential of electrodes to be low enough that they match the solar photon flux, producing a high current density and consequently increasing the yield of this important electrochemical process. ${ }^{4}$ To date, Pt-group metals have been the most effective catalysts in HER. ${ }^{5,6}$ However, the high material costs and limited resource of these catalysts hinder the hydrogen economy. ${ }^{7-9}$ Alternative low-cost materials for such applications are still in urgent demand..$^{\mathbf{1 0 , 1 1}}$

Molybdenum disulfide $\left(\mathrm{MoS}_{2}\right)$, a typical member of transition metal sulfides, has a layered structure held together by weak van der Waals forces. It is abundant, geographically ubiquitous, and a potentially cheap graphene analogue material. ${ }^{12}$ Recent reports that investigated $\mathrm{MoS}_{2}$ found it to be a competitive

${ }^{a}$ MEMS Center, Harbin Institute of Technology, Harbin, China. E-mail: yufeng_zhang@hit.edu.cn

${ }^{b}$ Key Laboratory of Micro-systems and Micro-Structures Manufacturing, Ministry of Education, Harbin, China

$\dagger$ Electronic supplementary information (ESI) available: Experimental details. See DOI: $10.1039 / \mathrm{c} 7 \mathrm{ra} 01605 \mathrm{k}$ electrocatalyst for HER, and both computational and experimental data suggested that the edge sites of $\mathrm{MoS}_{2}$ nanoparticles are the active sites, so interest in using $\mathrm{MoS}_{2}$ as water-splitting electrocatalyst has intensified. ${ }^{13-15}$ However, the poor intrinsic conductivity of $\mathrm{MoS}_{2}$ materials is a matter of concern because it suppresses charge transport. ${ }^{16,17}$ Taking this factor into account, we hypothesized that designing $\mathrm{MoS}_{2}$-based materials with more active edge sites and good conductivity would be an effective way to improve the electrocatalytic HER.

Earth-abundant $\mathrm{Cu}$-based materials have recently attracted more attention, particularly due to their favourable electrical conductivity and low-cost. ${ }^{18}$ Meanwhile, according to a volcano plot of the exchange current density as a function of the DFTcalculated Gibbs free energy of adsorbed atomic hydrogen, the value of $\mathrm{Cu}$ just lies below those of the noble Pt-group metals. ${ }^{19}$ The combination of $\mathrm{Cu}$ with $\mathrm{MoS}_{2}$ appears to be a promising way to increase the conductivity and improve the HER performance. Herein, compared with the $\mathrm{Cu} / \mathrm{MoS}_{2}$-based catalyst reported in previous works, ${ }^{20,21}$ we have creatively directly prepared the $\mathrm{Cu} /$ $\mathrm{MoS}_{2}$ nano-assembled structure for high HER activity using a more facile one-step microwave-assisted synthesis.

\section{Experimental details}

\subsection{Preparation of $\mathrm{Cu} / \mathrm{MoS}_{2}$ nano-assembled structure}

The $\mathrm{Cu} / \mathrm{MoS}_{2}$ nano-assembled structure (NAS) was prepared by the one-step microwave-assisted method. Sodium molybdate (242 mg), thiourea $(286 \mathrm{mg})$, and $\mathrm{CuCl}_{2} \cdot 2 \mathrm{H}_{2} \mathrm{O}(2.18 \mathrm{mg})$ were added to $60 \mathrm{~mL}$ of a mixture solution of isopropyl alcohol and ethylene glycol (EG) $(\mathrm{v} / \mathrm{v}=1: 4)$ and sonicated for $30 \mathrm{~min}$. A $1 \mathrm{M}$ $\mathrm{NaOH} / \mathrm{EG}$ solution was added to the mixture until a pH of 12 was 
reached, and then argon was blown into the mixture for $20 \mathrm{~min}$. The mixture was microwaved for $120 \mathrm{~s}$ at a dynamic power of $1700 \mathrm{~W}$ by a microwave oven (Panasonic NE-1753) in a draught cupboard and then cooled naturally. Next, $1 \mathrm{M}$ dilute nitric acid was added until a $\mathrm{pH}$ of 2 was reached. The product was collected by vacuum filtration and vacuum-dried at $60{ }^{\circ} \mathrm{C}$. For comparison, Cu-modified $\mathrm{MoS}_{2}$ nanosheets $\left(\mathrm{Cu} / \mathrm{MoS}_{2} \mathrm{NSs}\right)$ were fabricated by using a similar method to that described above, but with the sodium molybdate and thiourea replaced by $20 \mathrm{mg}$ of $\mathrm{MoS}_{2}$ NSs. (The detailed synthesis procedure of the $\mathrm{MoS}_{2}$ NSs and the $\mathrm{Cu} / \mathrm{MoS}_{2}$ NSs material can be found in the ESI section. $\dagger$ The TEM images of the $\mathrm{MoS}_{2}$ NSs were shown in Fig. S1. $\dagger$ )

\subsection{Material characterization}

The morphologies of the electrocatalysts were observed by transmission electron microscopy (TEM) using a microscope operated at an accelerating voltage of $300 \mathrm{keV}$. X-ray diffraction (XRD) profiles of $\mathrm{Cu} / \mathrm{MoS}_{2}$ NAS with high-intensity $\mathrm{Cu} \mathrm{K} \alpha$ radiation $(\lambda=1.5406 \mathrm{~nm})$ in the range of $10-90^{\circ}$. X-ray photoelectron spectroscopy (XPS) was used to record the elemental composition and the electron binding energy using a K-Alpha instrument.

\subsection{Modification of the glassy carbon electrode}

$4 \mathrm{mg}$ of the synthesized $\mathrm{Cu} / \mathrm{MoS}_{2}$ NAS catalysts and $80 \mu \mathrm{L}$ of 5 wt\% Nafion solution were dispersed in $1 \mathrm{~mL}$ of a water/ethanol mixture $(3: 1 \mathrm{v} / \mathrm{v})$ followed by a sonication for $15 \mathrm{~min}$ to obtain a homogeneous catalytic slurry. Afterward, a glassy carbon electrode (GCE) with a diameter of $3 \mathrm{~mm}$, which was polished by alumina suspensions, was treated with $5 \mu \mathrm{L}$ of the catalytic slurry and dried at a temperature of $26{ }^{\circ} \mathrm{C}$ (loading $0.285 \mathrm{mg}$ $\mathrm{cm}^{-2}$ ). In addition, $\mathrm{Cu} / \mathrm{MoS}_{2}$ NSs, $\mathrm{MoS}_{2}$ NSs, small-sized $\mathrm{MoS}_{2}$ NSs and Pt/C modified electrodes were prepared by the same method for comparison purposes.

\subsection{Electrochemical evaluation}

The HER activities of these catalysts were evaluated via linear sweep voltammetry (LSV) in $0.5 \mathrm{M} \mathrm{H}_{2} \mathrm{SO}_{4}$ solution at a scan rate of $5 \mathrm{mV} \mathrm{s}^{-1}$ and at a temperature of $26^{\circ} \mathrm{C}$. All electrochemical measurements were conducted using an electrochemical workstation (CHI 660D) and a standard three-electrode setup containing a saturated calomel electrode (SCE) as the reference electrode, a graphite rod as the counter electrode, and the modified GCEs as working electrodes. The AC impedance measured in the frequency range between $10^{6} \mathrm{~Hz}$ and $0.02 \mathrm{~Hz}$ with an AC voltage of $5 \mathrm{mV}$. Before electrochemical measurement, all polarization curves reported in our work were treated for IR loss and all of the potentials were calibrated to a reversible hydrogen electrode (RHE) by adding a value of $(0.241+$ $0.059 \mathrm{pH}) \mathrm{V}$ and the utilized electrolytes were degassed by bubbling Ar gas for $1 \mathrm{~h}$.

\section{Results and discussion}

The morphologies of $\mathrm{Cu} / \mathrm{MoS}_{2}$ NAS and $\mathrm{Cu} / \mathrm{MoS}_{2}$ NSs were characterized by transmission electron microscopy (TEM).
Fig. 1a gives a close-up view of Cu nanoparticles (NPs) uniformly distributed on $\mathrm{MoS}_{2}$. The mean size of $\mathrm{Cu}$ NPs, extracted by directly measuring 138 particles from the TEM, is estimated to be approximately $5.8 \mathrm{~nm}$. Fig. 1b shows an HRTEM image of the $\mathrm{Cu} / \mathrm{MoS}_{2}$ NAS with a lattice spacing of $0.24 \mathrm{~nm}$, corresponding to the (111) plane of $\mathrm{Cu}^{22}$ Also visible is the clear lattice fringes of $\mathrm{MoS}_{2}$. As shown in Fig. 1c and Fig. S2, $\dagger$ TEM was used to observe the morphology of $\mathrm{Cu} / \mathrm{MoS}_{2}$ NSs, in which Cu NPs (with a diameter of $12.5 \mathrm{~nm}$ ) aggregated on the surface of $\mathrm{MoS}_{2} \mathrm{NSs}$. HRTEM (Fig. 1d) indicated that having many highly crystalline $\mathrm{Cu}$ NPs covering the edges of $\mathrm{MoS}_{2}$ NSs may lead to the reduction of HER electrocatalytic performance.

Fig. 2a shows the XRD pattern of the $\mathrm{Cu} / \mathrm{MoS}_{2}$ NAS. For the pattern of the sample, the peaks at $2 \theta=14.2^{\circ}, 33.0^{\circ}, 39.7^{\circ}$, and $59.1^{\circ}$ are attributed to the (002), (100), (103) and (110) planes of $\mathrm{MoS}_{2} \cdot{ }^{23}$ The peaks of $\mathrm{Cu}$ at $43.5^{\circ}, 50.5^{\circ}$ and $74.5^{\circ}$ in the range of $40-80^{\circ}$ can be assigned to the diffraction from the (111), (200), (220) planes of reductive $\mathrm{Cu}$ NPs with cubic phase, respectively. ${ }^{24}$ XPS spectra were recorded to gain further insights into the chemical nature and bonding state of the $\mathrm{Cu} / \mathrm{MoS}_{2}$ NAS. As shown in Fig. 2b, the high-resolution Mo 3d XPS spectrum contains two strong characteristic peaks at $228.9 \mathrm{eV}$ and $231.9 \mathrm{eV}$, which can be attributed to the $\mathrm{Mo}^{4+}$ oxidation state, ${ }^{25}$ while the relatively weak peak detected at $235.7 \mathrm{eV}$ corresponds to the $\mathrm{Mo}^{6+}$ oxidation state (the latter feature most likely resulted from the formation of a very small amount of $\mathrm{MoO}_{3}$ species during catalyst preparation). Hence, the majority of the synthesized Mo species exhibited an oxidation state of +4 . Furthermore, the high-resolution $S 2 p_{1 / 2}$ and $S 2 p_{3 / 2}$ spectra, which were centred at $161.8 \mathrm{eV}$ and $162.9 \mathrm{eV}$, respectively, revealed the presence of divalent $\mathrm{S}^{2-}$ ions (Fig. 2c). ${ }^{26}$ After peak deconvolution of $\mathrm{Cu} 2 \mathrm{p}_{3 / 2}$ in Fig. 2d, XPS spectrum peaks centred at 935.4 and $932.7 \mathrm{eV}$ can be assigned as $\mathrm{CuO}$ and $\mathrm{Cu}_{2} \mathrm{~S}^{27}$

Different polarization curves obtained for the studied catalysts via LSV are shown in Fig. 3a. It was found that the Pt/C

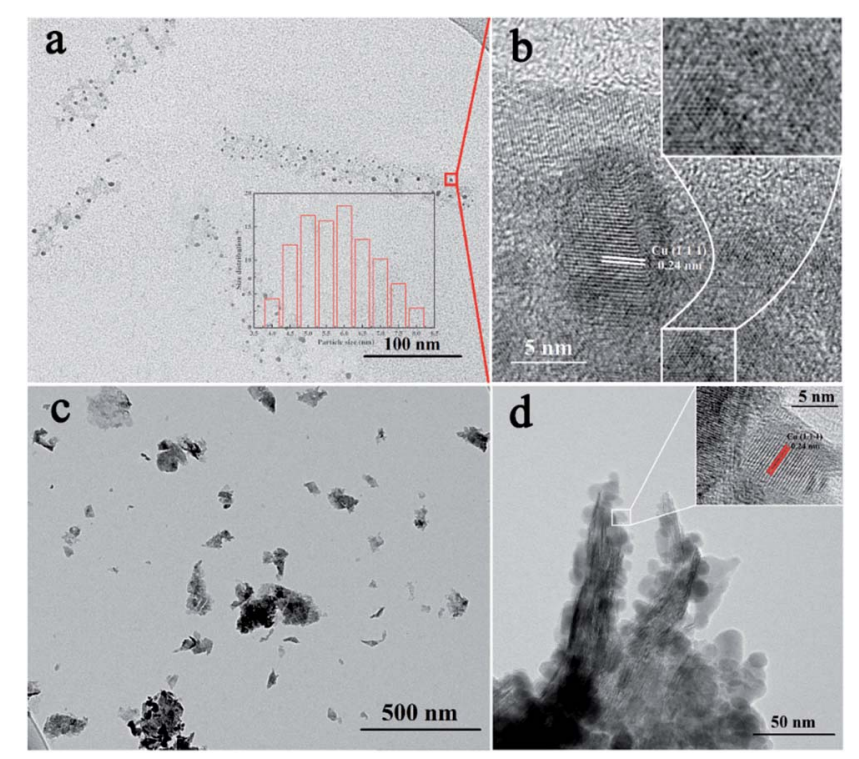

Fig. 1 TEM images of Cu/MoS 2 NAS (a) and Cu/MoS NSs (c). HRTEM images of $\mathrm{Cu} / \mathrm{MoS}_{2} \mathrm{NAS}(\mathrm{b})$, and $\mathrm{Cu} / \mathrm{MoS}_{2} \mathrm{NSs}$ (d). 

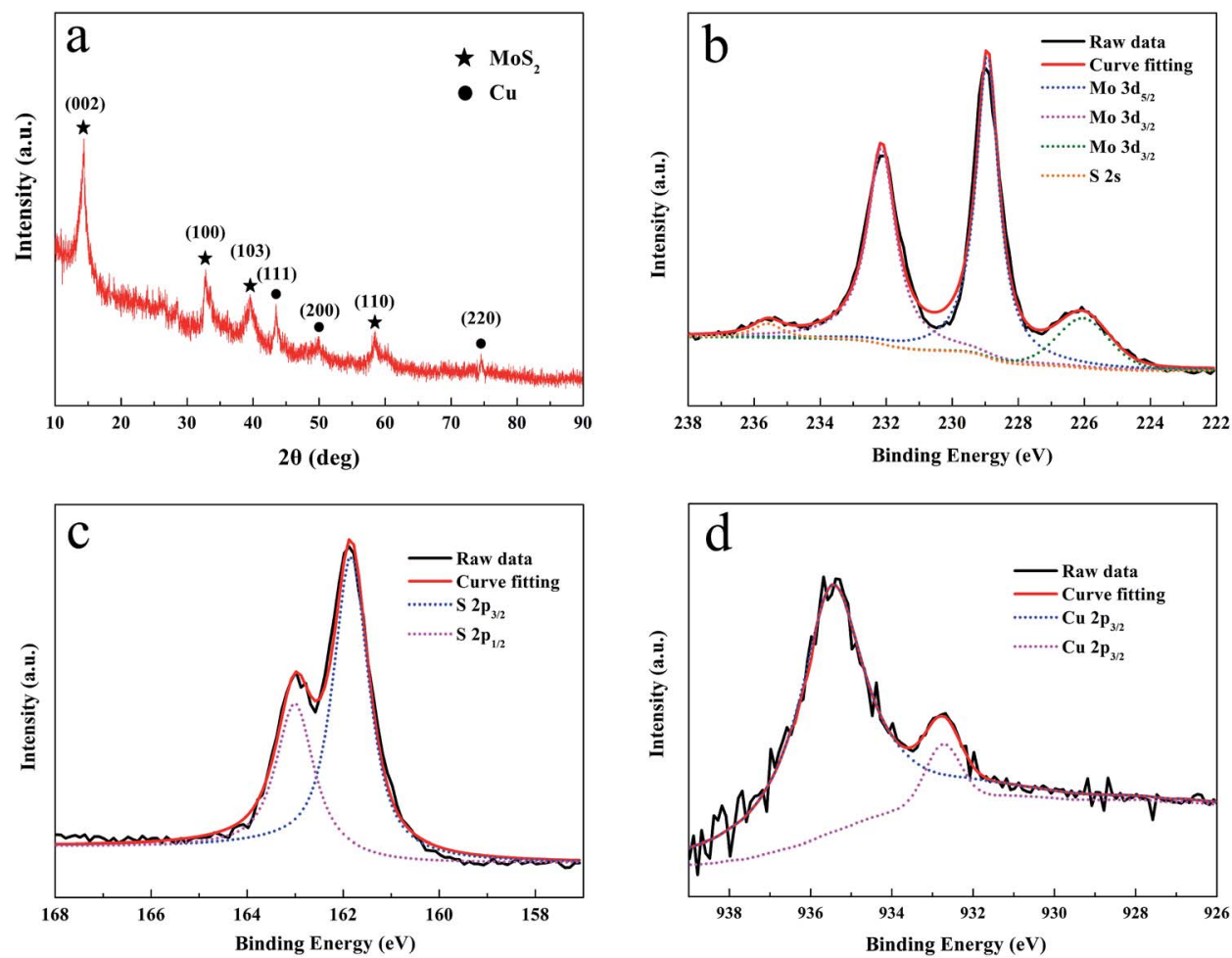

Fig. 2 XRD pattern of Cu/MoS 2 NAS (a). XPS images of Mo 3d (b), S 2p (c), and Cu $2 p$ (d).

catalyst exhibited very strong HER performance with an overpotential close to zero, while the $\mathrm{Cu} / \mathrm{MoS}_{2}$ NAS was characterized by a small overpotential of approximately $120 \mathrm{mV}$. For comparison, small-sized $\mathrm{MoS}_{2}$ NSs without $\mathrm{CuCl}_{2} \cdot 2 \mathrm{H}_{2} \mathrm{O}$ are fabricated by using a similar method to that described for $\mathrm{Cu}$ / $\mathrm{MoS}_{2}$ NAS synthesized (Fig. S3 and S4 $\dagger$ ). In a sharp contrast, both the $\mathrm{Cu} / \mathrm{MoS}_{2}$ NSs, pure $\mathrm{MoS}_{2}$ NSs, and small-sized $\mathrm{MoS}_{2}$ NSs exhibited poor HER electrocatalytic activity. The linear segments of the corresponding Tafel plots (Fig. 3b) were fit with the Tafel equation $\eta=b \times \lg j+a$, where $j$ is the current density, and $b$ is the Tafel slope. As a result, the Tafel slopes of 92, 83, 66, 55 , and $34 \mathrm{mV}$ per decade were obtained for $\mathrm{MoS}_{2}$ NSs, smallsized $\mathrm{MoS}_{2}$ NSs, $\mathrm{Cu} / \mathrm{MoS}_{2}$ NSs, Cu/MoS 2 NAS, and Pt/C catalyst, respectively. It is indicated that the improved performance of the catalyst is contributed to the introducing of Cu NPs which is in accordance with previous reports. ${ }^{20,21}$ The high HER catalytic activity of the prepared $\mathrm{Cu} / \mathrm{MoS}_{2}$ NAS catalyst can be attributed to the strong electronic coupling between the $\mathrm{Cu}$ and $\mathrm{MoS}_{2}$. To maximize this effect, impedance measurements were performed at an overpotential of $\eta=120 \mathrm{mV}$. As shown in Fig. 3c, the same amount of the $\mathrm{Cu} / \mathrm{MoS}_{2}$ NAS catalyst exhibited an alternating current impedance of approximately $275 \Omega$, which was much lower than that of the $\mathrm{MoS}_{2}$ NSs (approximately $1800 \Omega$ ) and $\mathrm{Cu} / \mathrm{MoS}_{2}$ NSs (approximately $370 \Omega$ ).

To further evaluate the long-term stability of the synthesized $\mathrm{Cu} / \mathrm{MoS}_{2}$ NAS catalyst, cyclic voltammetry (CV) measurements by scanning 2000 cycles from $-300 \mathrm{mV}$ to $300 \mathrm{mV}$ (vs. RHE) with a scan rate of $100 \mathrm{mV} \mathrm{s}^{-1}$ in an acidic environment $(0.5 \mathrm{M}$ $\mathrm{H}_{2} \mathrm{SO}_{4}$ ) was used. Fig. $3 \mathrm{~d}$ shows the comparison of polarization curves of the catalyst during the first cycle and $2000^{\text {th }}$ cycle. The almost overlapped curves indicate the negligible loss of the catalytic performance and a remarkable stability of the $\mathrm{Cu} / \mathrm{MoS}_{2}$ NAS catalyst. ${ }^{28}$ In addition, the TEM images depicted in the insert of Fig. $3 \mathrm{~d}$ show that the original morphology of the hybrid catalyst was well preserved after acidic treatment.

Remarkably, Tafel slopes are one of the most significant factors that can discern the HER mechanism. According to the classic theory, ${ }^{29}$ Tafel slopes for the typical Volmer, Heyrovsky, and Tafel reactions are around of $120 \mathrm{mV} \mathrm{dec}^{-1}, 40 \mathrm{mV} \mathrm{dec}^{-1}$, and $30 \mathrm{mV} \mathrm{dec}^{-1}$, respectively (1-3). The following are the now accepted steps by which HER in acidic aqueous media described, where $\mathrm{MH}_{\mathrm{ads}}$ represents a hydrogen atom chemically adsorbed on an active site of various material (M). In view of the Tafel slope of $55 \mathrm{mV} \mathrm{dec}{ }^{-1}$ for the $\mathrm{Cu} / \mathrm{MoS}_{2}$ NAS catalyst in the current work, a combination of the Volmer reaction, involving an electrochemical desorption step that converts protons into absorbed hydrogen atoms on the catalyst surface, and the Heyrovsky reaction, involving the formation of surface scope hydrogen molecules, should dominate the HER on the catalytic process of the $\mathrm{Cu} / \mathrm{MoS}_{2}$ NAS catalyst. In other words, the rate determining step is the electrochemical desorption of $\mathrm{H}_{\mathrm{ads}}$ and $\mathrm{H}_{3} \mathrm{O}^{+}$to form hydrogen, and the HER occurs through a VolmerHeyrovsky mechanism.

$$
\begin{gathered}
\mathrm{H}_{3} \mathrm{O}^{+}+\mathrm{e}^{-}+\mathrm{C} \rightarrow \mathrm{MH}_{\mathrm{ads}}+\mathrm{H}_{2} \mathrm{O} \\
\mathrm{H}_{3} \mathrm{O}^{+}+\mathrm{e}^{-}+\mathrm{MH}_{\mathrm{ads}} \rightarrow \mathrm{C}+\mathrm{H}_{2}+\mathrm{H}_{2} \mathrm{O} \\
\mathrm{MH}_{\mathrm{ads}}+\mathrm{MH}_{\mathrm{ads}} \rightarrow 2 \mathrm{M}+\mathrm{H}_{2}
\end{gathered}
$$



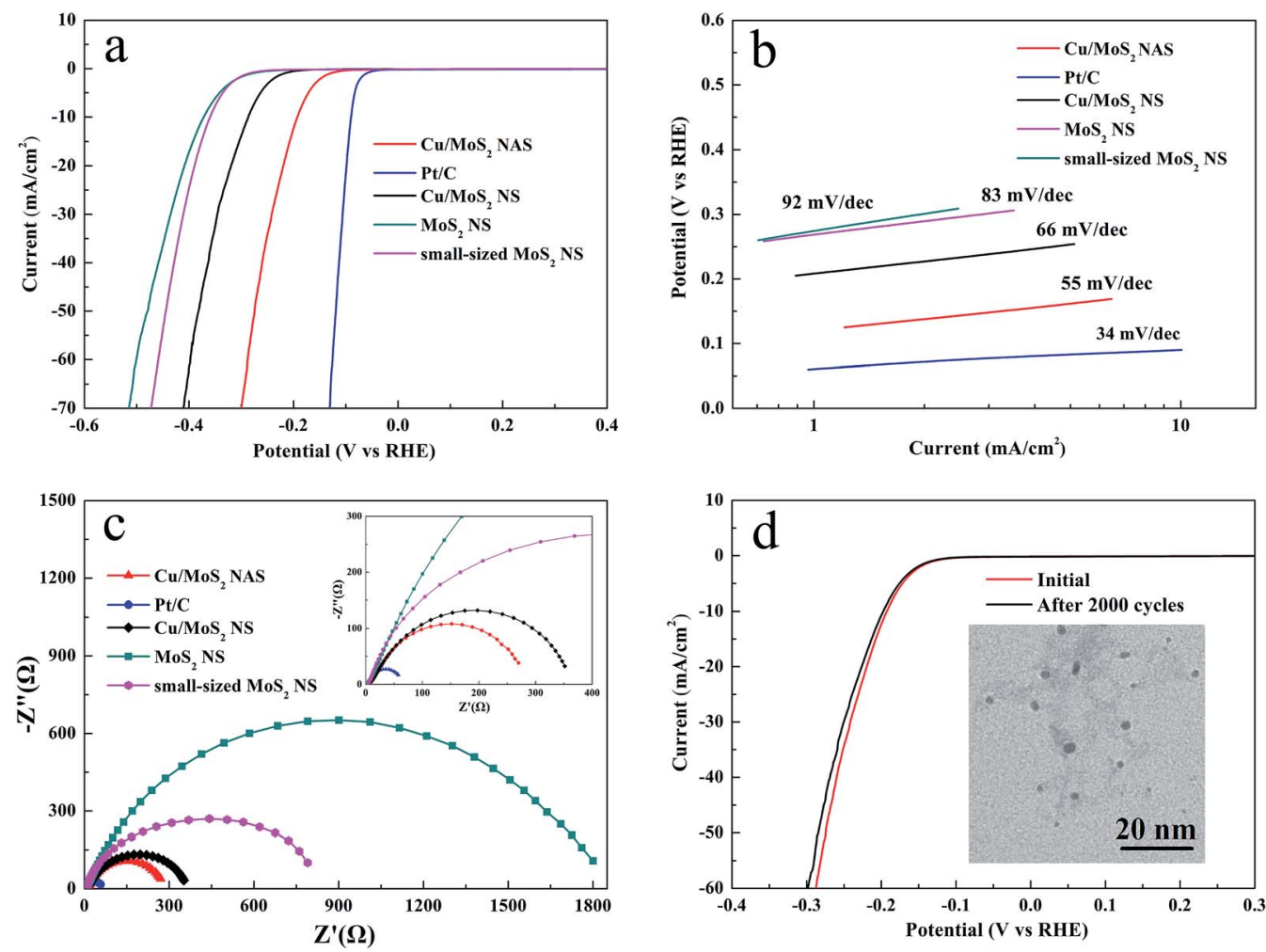

Fig. 3 Polarization curves for catalysts (a) and the corresponding Tafel plots (b). Impedance spectroscopy at an overpotential of 120 mV (c). Durability test for the $\mathrm{Cu} / \mathrm{MoS}_{2} \mathrm{NAS}(\mathrm{d})$.

To elucidate the synergistic effect produced by the synthesized $\mathrm{Cu} / \mathrm{MoS}_{2}$ NAS catalyst on the catalytic process in more detail, a simple model (Fig. 4) can be considered. The obtained hybrid contains a large number of active HER catalytic sites due to the abundance of accessible edges resulting from the small size and irregular shape of $\mathrm{MoS}_{2}$. The use of Cu NPs not only improved the electrical conductivity of the catalyst but also further enhanced the catalytic activity by a synergistic effect with nano-sized $\mathrm{MoS}_{2}$. Therefore, the produced $\mathrm{Cu} / \mathrm{MoS}_{2}$ NAS

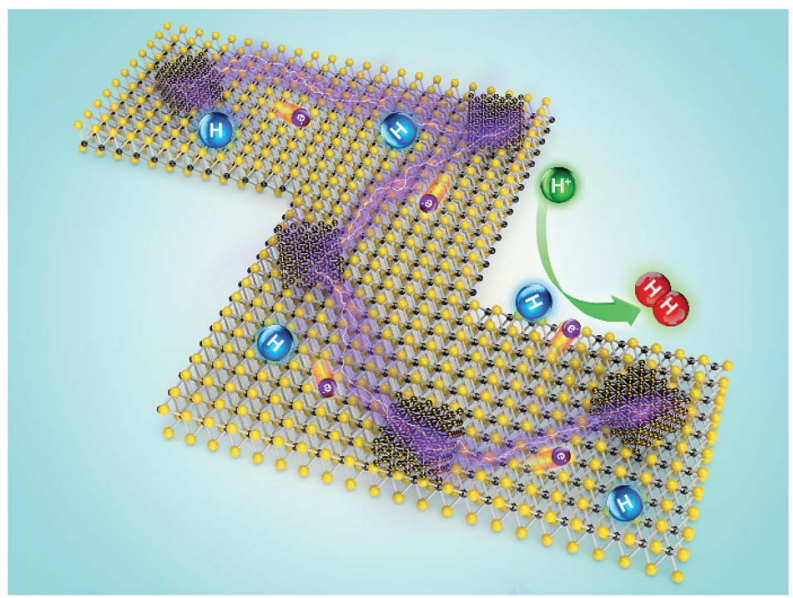

Fig. 4 Schematic illustration of the mechanism governing the electrocatalytic HER on the $\mathrm{Cu} / \mathrm{MoS}_{2}$ NAS. catalyst can effectively reduce dissociated $\mathrm{H}^{+}$ions and release $\mathrm{H}_{2}$ molecules on a large number of active sites.

\section{Conclusions}

In summary, a facile microwave-assisted method has been used to synthesize a $\mathrm{Cu} / \mathrm{MoS}_{2}$ NAS catalyst for HER. TEM images show that $\mathrm{Cu}$ NPs can disperse on $\mathrm{MoS}_{2}$ uniformly, which improves conductivity. The $\mathrm{Cu} / \mathrm{MoS}_{2}$ NAS exhibits excellent HER catalytic properties and long cycle life, which is attributed to the excellent electrical coupling between the Cu NPs and the nano-sized $\mathrm{MoS}_{2}$. Therefore, this work describes an inexpensive method for the efficient fabrication of a $\mathrm{Cu} / \mathrm{MoS}_{2}$ NAS catalyst for the HER.

\section{Acknowledgements}

The work described in this paper was financially supported by the National Natural Science Foundation of China (No. 61404037 and No. 61376113).

\section{Notes and references}

1 H. I. Karunadasa, C. J. Chang and J. R. Long, Nature, 2010, 464, 1329-1333.

2 J. A. Turner, Science, 2004, 305, 972-974.

3 J. S. Luo, J. H. Im, M. T. Mayer, M. Schreier, M. K. Nazeeruddin, N. G. Park, S. D. Tilley, H. J. Fan and M. Grätzel, Science, 2014, 345, 1593-1596. 
4 M. G. Walter, E. L. Warren, J. R. McKone, S. W. Boettcher, Q. Mi, E. A. Santori and N. S. Lewis, Chem. Rev., 2010, 110, 6446-6473.

5 C. Chen, Y. J. Kang, Z. Y. Huo, Z. G. Zhu, W. Y. Huang, H. L. Xin, J. D. Snyder, D. Li, J. A. Herron, M. Mavrikakis, M. Chi, K. L. More, Y. Li, N. M. Markovic, G. A. Somorjai, P. Yang and V. R. Stamenkovic, Science, 2014, 343, 13391343.

6 T. Ye, L. B. Lv, M. Xu, B. Zhang, K. X. Wang, J. Su, X. H. Lin and J. S. Chen, Nano Energy, 2015, 15, 335-342.

7 Y. Shi, J. Wang, C. Wang, T. T. Zhai, W. J. Bao, J. J. Xu, X. H. Xia and H. Y. Chen, J. Am. Chem. Soc., 2015, 137, 7365-7370.

8 F. K. Ma, Y. Z. Wu, Y. L. Shao, Y. Y. Zhong, J. X. Lv and X. P. Hao, Nano Energy, 2016, 27, 466-474.

9 W. X. Zhu, C. Tang, D. N. Liu, J. L. Wang, A. M. Asiric and X. P. Sun, J. Mater. Chem. A, 2016, 4, 7169-7173.

10 Y. J. Tang, Y. Wang, X. L. Wang, S. L. Li, W. Huang, L. Z. Dong, C. H. Liu, Y. F. Li and Y. Q. Lan, Adv. Energy Mater., 2016, 6, 1600116.

11 Y. C. Zhoua, Y. H. Leng, W. J. Zhou, J. L. Huang, M. W. Zhao, J. Zhan, C. H. Feng, Z. H. Tang, S. W. Chen and H. Liu, Nano Energy, 2015, 16, 357-366.

12 B. W. Jin, X. M. Zhou, L. Huang, M. Licklederer, M. Yang and P. Schmuki, Angew. Chem., Int. Ed., 2016, 55, 12252-12256.

13 T. F. Jaramillo, K. P. Jørgensen, J. Bonde, J. H. Nielsen, S. Horch and I. Chorkendorff, Science, 2007, 317, 100-102.

14 J. Bonde, P. G. Moses, T. F. Jaramillo, J. K. Nørskovb and I. Chorkendorff, Faraday Discuss., 2008, 140, 219-231.

15 B. Hinnemann, P. G. Moses, J. Bonde, K. P. Jørgensen, J. H. Nielsen, S. Horch, I. Chorkendorff and J. K. Nørskov, J. Am. Chem. Soc., 2005, 127, 5308-5309.
16 Z. Y. Zhang, W. Y. Li, M. F. Yuena, T. W. Nga, Y. B. Tang, C. S. Lee, X. F. Chenc and W. J. Zhang, Nano Energy, 2015, 18, 196-204.

17 Q. H. Wang, K. K. Zadeh, A. Kis, J. N. Coleman and M. S. Strano, Nat. Nanotechnol., 2012, 7, 699-712.

18 M. B. Gawande, A. Goswami, F. X. Felpin, T. Asefa, X. X. Huang, R. Silva, X. X. Zou, R. Zboril and R. S. Varma, Chem. Rev., 2016, 116, 3722-3811.

19 D. Merki and X. Hu, Energy Environ. Sci., 2011, 4, 3878-3888. 20 F. Li, J. Li, X. Lin, X. Li, Y. Fang, L. Jiao, X. An, Y. Fu, J. Jin and R. Li, J. Power Sources, 2015, 300, 301-308.

21 F. Li, L. Zhang, J. Li, X. Lin, X. Li, Y. Fang, J. Huang, W. Li, M. Tian, J. Jin and R. Li, J. Power Sources, 2015, 292, 15-22.

22 R. Krishna, D. M. Fernandes, J. Ventura, C. Freire and E. Titus, Int. J. Hydrogen Energy, 2016, 41, 11608-11615.

23 G. Du, Z. Guo, S. Wang, R. Zeng, Z. Chen and H. Liu, Chem. Commun., 2010, 46, 1106-1108.

24 J. Luo, S. Jiang, H. Zhang, J. Jiang and X. Liu, Anal. Chim. Acta, 2012, 709, 47-53.

25 B. J. Guo, K. Yu, H. L. Li, H. L. Song, Y. Y. Zhang, X. Lei, H. Fu, Y. H. Tan and Z. Q. Zhu, ACS Appl. Mater. Interfaces, 2016, 8, 5517-5525.

26 K. C. Pham, Y. H. Chang, D. S. McPhail, C. Mattevi, A. T. S. Wee and D. H. C. Chua, ACS Appl. Mater. Interfaces, 2016, 8, 5961-5971.

27 M. Sam, M. R. Bayati, M. Mojtahedi and K. Janghorban, Appl. Surf. Sci., 2010, 257, 1449-1453.

28 H. Deng, C. Zhang, Y. Xie, T. Tumlin, L. Giri, S. P. Karna and J. Lin, J. Mater. Chem. A, 2016, 4, 6824-6830.

29 J. G. N. Thomas, Trans. Faraday Soc., 1961, 57, 1603-1611. 